\title{
Het correctief referendum en de opgeschroefde uitkomstdrempel: vragen om problemen*
}

\author{
Frank Hendriks**
}

\section{Naar een correctief referendum met opgeschroefde uitkomstdrempel?}

Op 26 januari 2021 stemde de Eerste Kamer met een nipte meerderheid in met het initiatiefvoorstel van SP-Kamerlid Ronald van Raak over opneming in de Grondwet van bepalingen voor een bindend correctief referendum. Na de verkiezingen van 17 maart 2021, ontbinding en herschikking van de Tweede Kamer, kan de tweede lezing in gang worden gezet waarvoor in beide Kamers een twee derde meerderheid moet worden behaald. Ook bij tweede lezing zal ongetwijfeld weer stevige discussie ontstaan over de hoog opgeschroefde uitkomstdrempel voor een geldige referendumuitslag. Deze is bij lezing in de Tweede Kamer toegevoegd aan het wetsvoorstel als gevolg van een aangenomen motie van Stieneke van der Graaf, Kamerlid voor de ChristenUnie. Het debat over dit amendement was in de Eerste Kamer nog feller dan in de Tweede Kamer.

In het kort bepaalt dit amendement dat de uitkomstdrempel - het percentage dat een winnende meerderheid moet behalen - in de Grondwet moet worden vastgelegd op een wijze die haast niet anders dan tot een bijzonder hoge drempel zal leiden. Een geldige winnende meerderheid is gedefinieerd als 'een meerderheid die ten minste gelijk is aan een meerderheid van het aantal bij de meest recente verkiezingen van de leden van de Tweede Kamer uitgebrachte geldige stemmen'. Bij een opkomst van circa 80 procent (niet ongebruikelijk bij Tweede Kamerverkiezingen in Nederland; bij de recente 'coronaverkiezingen' van 17 maart 2021 was de opkomst nog steeds 78,7 procent; in 2017 was de opkomst 81,5 procent) zal zo'n uitkomstdrempel rond de 40 procent van de kiesgerechtigden uitkomen. Dit zou een aanmerkelijk hogere drempel zijn dan de uitkomstdrempel van 33,3 procent die was geadviseerd door de Staatscommissie Parlementair Stelsel onder leiding van VVD-coryfee Johan Remkes.

Is het zinvol om de uitkomstdrempel zo hoog op te schroeven, en is het wijs om dit in de Grondwet vast te klinken? In beide gevallen zijn er zware argumenten die hiertegen pleiten. In mijn bijdrage aan dit Dossier ga ik eerst in op de gewenste functies van een correctief wetgevingsreferendum en een daaraan gekoppelde uitkomstdrempel, vervolgens op de noodzaak van een verstandig referendumontwerp en de gewenste ruimte voor ervaringsleren, waarna enkele conclusies volgen. En

* Deze tekst is een lichte bewerking van het advies dat de auteur op verzoek van de Eerste Kamer schreef over de mogelijk verhoogde uitkomstdrempel voor correctieve referenda.

** Prof. dr. Frank Hendriks is hoogleraar vergelijkende bestuurskunde aan Tilburg University. 
passant ga ik in op drempels die andere landen voor correctieve wetgevingsreferenda hanteren en de logica die daarin te onderkennen is. ${ }^{1}$

\section{Gewenste functies correctief referendum: noodrem en stok achter de deur}

Bij het nadenken over correctieve wetgevingsreferenda en daaraan verbonden drempelwaarden is het cruciaal de gewenste en bedoelde functies daarvan voor ogen te houden. Ik noem de twee belangrijkste functies in het licht van de hier voorliggende kwestie.

Ten eerste: de corrigerende functie achteraf. Een correctief wetgevingsreferendum kan dienen als noodrem, als laatste redmiddel voor wetgeving die dreigt te ontsporen. In de coalitiedynamiek kan regelgeving ontstaan waarvoor een (nipte) coalitiemeerderheid kan worden geconstrueerd, maar waarvoor onvoldoende maatschappelijke steun is: de Ostrogorski-paradox. De Staatscommissie Parlementair Stelsel beveelt tegen deze achtergrond het bindend correctief wetgevingsreferendum aan, met daaraan gekoppeld een relatief strenge uitkomstdrempel van een derde (33,3 procent) van de kiesgerechtigde bevolking.

De uitkomstdrempel is een alternatief voor de opkomstdrempel, eerder bij het raadgevend referendum toegepast, die in de praktijk perverse effecten blijkt mee te brengen: voorstanders van de aangevochten wetgeving hebben een incentive om weg te blijven bij de stembus omdat ze daarmee de kans verkleinen dat de tegenstanders winnen met een rechtsgeldige uitslag. Een uitkomstdrempel vergroot de kans dat de uitslag de verhoudingen tussen voorstanders en tegenstanders meer realistisch weergeeft. Sommigen zouden de correctie op wetgeving in het geheel niet met drempels willen belasten. Het nadeel daarvan is dat een kleine meerderheid (50 procent +1 is genoeg) van een potentieel kleine minderheid (zonder ondergrens) al vetomacht kan verkrijgen ten aanzien van parlementair vastgestelde wetgeving.

De Staatscommissie Parlementair Stelsel $(2018,153)$ noemt een uitkomstdrempel van 33,3 procent een 'weliswaar haalbare maar zeker niet eenvoudig te nemen horde'. Het beeld van de noodrem in de trein dringt zich op: die zit gewoonlijk achter glas en hangt vrij hoog om al te lichtvaardig of ongelukkig gebruik te ontmoedigen, maar niet zo dat gebruik schier onmogelijk wordt gemaakt. In het laatste geval verliest de noodrem haar functie. En de nauw verbonden tweede kernfunctie raakt dan ook uit beeld.

Als tweede kernfunctie geldt: de alerteringsfunctie vooraf. Een correctief wetgevingsreferendum geeft ook vooraf, als wetgeving nog niet parlementair is vastgesteld, nuttige prikkels en waarschuwingssignalen af. Bestuurders die weten dat hun wetgevende arbeid effectief betwist kan worden, gaan hun wetgevende arbeid met vergrote alertheid in. In Zwitserland staat dit bekend als de Neidhart-these in het kort: de mogelijkheid van een tik op de vingers verderop in het traject stimuleert het zoeken naar draagvlak en het verkennen van sterke en zwakke signalen van weerstand eerder in het traject. Anders gezegd: de aanwezigheid van een reëel 
wetgevingscorrectief leidt tot activiteiten die daadwerkelijke activering van het wetgevingscorrectief moeten voorkomen. ${ }^{2}$ Deze onderliggende functie van het correctief wetgevingsreferendum - als spreekwoordelijke stok achter de deur - vereist een reële kans op activering van het instrument. Het werkt niet als het zeer onwaarschijnlijk is dat men ooit met de betreffende 'stok' te maken kan krijgen.

Soms wordt nog een derde voordeel verbonden aan een bindend correctief referendum: de participatiekloof tussen hoger en lager opgeleiden is bij referenda, waaronder correctieve referenda, minder groot dan bij andere vormen van interactie tussen bestuur en samenleving. We moeten ons echter afvragen of dit een kernfunctie is van een instrument dat niet in aanleg als participatietrekker is bedoeld, maar als ultimum remedium voor uitzonderlijke situaties. Net als bij een noodrem in de trein is breed gebruik van de voorziening in eerste aanleg geen prioriteit.

\section{Verstandig ontwerp: 33,3 procent is al aan de hoge kant}

De twee kernfuncties hangen samen en vragen om een verstandig ontwerp. Hier is eerder en elders over nagedacht. In Zwitserland hanteert men bij het correctieve wetgevingsreferendum drempels voor het aantal te verzamelen handtekeningen waarmee een dergelijk referendum kan worden afgedwongen (50.000), maar geen opkomst- of uitkomstdrempel voor het verkrijgen van een geldige meerderheid (een gewone meerderheid van 50 procent +1 van de stemmen volstaat). ${ }^{3}$

Andere landen met nationale voorzieningen voor een correctief wetgevingsreferendum op burgerinitiatief hanteren in veel gevallen een opkomstdrempel en in enkele gevallen een uitkomstdrempel zoals de Staatscommissie aanbeveelt in lijn met veel van de actuele literatuur ter zake. Slovenië kent een uitkomstdrempel van 20 procent voor aangevochten reguliere wetgeving. Litouwen combineert een uitkomstdrempel van 25 procent met een opkomstdrempel van 50 procent voor reguliere wetgeving en vereist een uitkomstdrempel van 33,3 procent voor constitutionele wetgeving. Dit is in lijn met de breder waargenomen regel dat voor constitutionele wetgeving en aanpassing daarvan zwaardere eisen gelden dan voor gewone wetgeving. ${ }^{4}$

In vergelijkend perspectief is een uitkomstdrempel van 33,3 procent voor gewone wetgeving zoals voorgesteld door de Staatscommissie aan de hoge kant. ${ }^{5}$ Bij een kiesgerechtigde bevolking van 12,8 miljoen komt dat neer op een meerderheid van circa 4,3 miljoen (of meer) vereiste tegenstemmers om een wet daadwerkelijk te kunnen verwerpen. De eerdere Wet raadgevend referendum hanteerde een opkomstdrempel van 30 procent van de kiesgerechtigde bevolking; een meerderheid van een kleine 2 miljoen tegenstemmers kon daarmee het pleit al beslechten. Bij het Oekraïne-referendum van 2016 trok het 'winnende' tegenkamp met 2,5 miljoen tegenstemmers aan het langste end; samen met ruim 1,5 miljoen voorstemmers kwam de opkomst op 32,2 procent en daarmee boven de opkomstdrempel uit. Een uitkomstdrempel van 33,3 procent (meer dan 4,3 miljoen tegenstemmers) zou hier bij lange na niet zijn gepasseerd. Het referendum over de Wet op de inlichtingen- en veiligheidsdiensten (Wiv) van 2018 kwam met 3,3 miljoen tegenstem- 
mers weliswaar wat dichterbij, maar zou voor deze uitkomstdrempel van 33,3 procent nog steeds één miljoen tegenstemmers te kort zijn gekomen. En het Wiv-referendum werd dan nog wel geholpen door samenvalling met de reguliere gemeenteraadsverkiezingen.

\section{Nog hoger is vragen om problemen}

Bij een nóg hogere drempel, een uitkomstdrempel die tot boven de 40 procent kan gaan, zal het nóg moeilijker worden, bijna onmogelijk, om reguliere wetgeving per correctief referendum daadwerkelijk te blokkeren; 5,1 miljoen of meer mensen zouden moeten tegenstemmen. Calculerende burgers en politici zullen dan licht tot de slotsom komen dat het correctief referendum geen reële noodrem en stok achter de deur is. Het correctief referendum verliest daarmee aan de twee samenhangende kernfuncties van correctie achteraf en alertering vooraf. In plaats van een reële noodrem en stok achter de deur kan het beeld van het correctief referendum als wassen neus of fopspeen licht postvatten.

Voor de politiek brengt een verder verhoogde uitkomstdrempel nog een extra nadeel met zich. Een correctief referendum met uitkomstdrempel resulteert in een geldige uitslag als ófwel het voorkamp ófwel het tegenkamp de drempel als meerderheid passeert. Alleen in het tweede geval wordt de betreffende wet, conform het voorstel van de Staatscommissie, verworpen; bij alle andere uitkomsten kan de wet formeel worden doorgezet. Maar informeel, voor het oog van de natie, zal de politieke meerderheid achter een aangevochten wet ook worden beoordeeld op haar vermogen om het 'tegenkamp' effectief weerstand te bieden, bij voorkeur met een geldige meerderheid onder het kiezersvolk. Zelf ver onder de lat blijven die voor een weerspannig burgerinitiatief 'moeilijk maar haalbaar' wordt geacht, zal geen sterke indruk maken.

\section{Vastspijkeren in de Grondwet belemmert ervaringsleren}

Ten slotte de vraag of een uitkomstdrempel (hoe hoog ook) in de Grondwet thuishoort of in de gewone (referendum)wet. Twee samenhangende argumenten pleiten voor het specificeren van een uitkomstdrempel in reguliere wetgeving en het hooguit benoemen van generieke principes in de Grondwet. Ten eerste: de Nederlandse Grondwet is in het algemeen een plek voor generieke principes en staat algemeen bekend als bijzonder moeilijk te wijzigen. Ten tweede: een verstandig referendumdesign vraagt om een zekere ruimte voor ervaringsleren; referenderen moet men leren, zeker als men er weinig ervaring mee heeft, zoals Nederland op nationaal niveau. De kans dat de fijnere details van het ontwerp, waaronder de exacte hoogte van de uitkomstdrempel, in één keer helemaal goed zijn, en dus met een gerust hart kunnen worden vastgespijkerd, is niet groot. Zeker bij een inhoudelijk kwetsbare norm - een onwaarschijnlijk hoge uitkomstdrempel - past prudentie. 
Ook als de uitkomstdrempel zoals voorgesteld door de Staatscommissie Parlementair Stelsel werd gevolgd, zou het verstandig zijn om: (a) dit te doen in de gewone (referendum)wet en niet in de Grondwet; (b) na verloop van tijd een grondige evaluatie in te bouwen met de mogelijkheid van verfijnde normstelling; en (c) dit laatste in handen te geven van een brede en gezaghebbende (referendum)commissie. De wetgever kan eventueel een bandbreedte voor mogelijke drempelwijzigingen aangeven (bijvoorbeeld 5 procent boven of onder de eerder in de wet vastgelegde norm). In de Grondwet zouden leidende principes in meer algemene zin passen.

\section{Conclusie: problemen zonder eenvoudige oplossing}

Bij het nadenken over correctieve wetgevingsreferenda en daaraan verbonden drempelwaarden is het noodzakelijk de gewenste correctie- en alerteringsfuncties voor ogen te houden. Bij een al te hoge uitkomstdrempel raken deze kernfuncties uit beeld en moet men zich afvragen of de voorziening van een bindend correctief referendum nog wel zin heeft. Noch de samenleving, noch de politiek wordt daar beter van. Internationaal vergeleken en bezien vanuit de gewenste kernfuncties zou een uitkomstdrempel van 20 à 25 procent in de rede liggen. De door de Staatscommissie voorgestelde uitkomstdrempel van 33,3 procent zoekt de bovengrens al op. Een uitkomstdrempel die richting 40 procent of meer beweegt, schiet daar ruim aan voorbij. Welke norm ook wordt gekozen, specificatie ervan past niet bij de Nederlandse Grondwet, maar bij de uit te werken referendumwet.

Dat een hoog opgeschroefde uitkomstdrempel grote, nadelige gevolgen kan hebben, was bij behandeling van het initiatiefwetsvoorstel voor het bindend correctief referendum in de Eerste Kamer een stuk dieper doorgedrongen dan bij de eerdere behandeling in de Tweede Kamer, waar het amendement ook pas te elfder ure ter tafel kwam. Dat de indienster zelf niet goed in staat bleek in het Kamerdebat het verschil uit te leggen tussen een opkomstdrempel en een uitkomstdrempel gaf te denken. In de Tweede Kamer stemden uiteindelijk alleen VVD, CDA, SGP en Denk tegen. In de Eerste Kamer stemden ook de fracties van PvdA en GroenLinks (minus één lid) tegen; twijfels over de uitzonderlijk hoge uitkomstdrempel vormden daarbij een belangrijke factor. Met 39 stemmen vóór kwam het initiatiefwetsvoorstel maar net boven de vereiste meerderheid van 38 Eerste Kamerleden.

De indiener van het initiatiefwetsvoorstel, Ronald van Raak van de SP, gaf meermaals aan dat de opgeschroefde uitkomstdrempel ook niet zijn persoonlijk keuze was; hij had het amendement in de Tweede Kamer ontraden. Na aanvaarding in de Tweede Kamer stelde hij zich evenwel op als 'procesbegeleider', zoals hij het noemde, de begeleider van referendumwetgeving op weg naar haalbare politieke meerderheden. In de Eerste Kamer betoogde hij dat het probleem van de hoog opgeschroefde uitkomstdrempel ook weer niet overdreven moest worden - ook als tegenstemmers de drempel niet halen kunnen ze een massief signaal aan politici geven, die daar het hunne mee kunnen en zullen doen - en bovendien geadresseerd kan worden door correctieve referenda (die gesteund door voldoende handtekenin- 
gen doorgang mogen krijgen) zo veel mogelijk te laten plaatsvinden op de dag dat ook Tweede Kamerverkiezingen plaatsvinden.

Het is waar dat de gewoonlijk hoge opkomst bij die verkiezingen de uitkomstdrempel voor een correctief referendum weer in beeld zou kunnen brengen. Tussendoor vinden evenwel ook algemene verkiezingen plaats met veel lagere opkomsten, en tussentijdse correctieve referenda kunnen ook daaraan worden gekoppeld. En als er haast geboden is, en geen algemene verkiezingen op afzienbare termijn in zicht zijn, kunnen correctieve referenda ook nog steeds op zichzelf komen te staan. Ongewenst bijeffect van een en ander zou zelfs kunnen zijn dat geplande wetgeving met grotere spoed ontwikkeld en ingediend gaat worden, om koppeling van een eventueel correctief wetgevingsreferendum aan parlementsverkiezingen aan het einde van een kabinetsperiode te kunnen ontlopen. Dit terwijl een correctief wetgevingsreferendum juist de dubbelfunctie zou moeten hebben van onbekookte wetgeving ontmoedigen en overhaaste wetgevers tot oplettendheid manen.

Kortom: eenvoudig is het probleem van de uitzonderlijk hoog opgeschroefde uitkomstdrempel niet op te lossen. Of het op termijn draaglijk is en op de koop toe genomen kan worden, is uiteindelijk niet wetenschappelijk te bepalen, maar moet maatschappelijk en politiek worden gewogen. We moeten zien tot hoeveel creativiteit en wijsheid de volksvertegenwoordiging in staat zal zijn bij tweede lezing van wetgeving voor het bindend correctief referendum.

\section{Noten}

1 Deze tekst is een bewerking van het advies dat de Eerste Kamer mij verzocht te schrijven op basis van mijn onderzoekservaring met het onderwerp. Onderliggend onderzoek is te vinden in: Hendriks, F., Krieken, K. van der \& Wagenaar, C. (2017). Democratische zegen of vloek: Aantekeningen bij het referendum. Amsterdam University Press; Hendriks, F., Jacobs, D. \& Wagenaar, C. (2019). Referenderen en delibereren: Een verkenning van bindend correctieve referenda en combinaties met deliberatieve democratie. Tilburg University.

2 Zonder opkomst- of uitkomstdrempel liep het afbreukrisico van wetgeving In Zwitserland historisch gezien niet de spuigaten uit. Sinds de introductie in 1874 tot en met de zomer van 2019 werden in totaal 194 correctieve referenda georganiseerd op federaal niveau. Ongeveer 6 procent van de totale federale wetgevingsproductie werd daarmee aangevochten; van dat (relatief kleine) deel draaide zo'n 57 procent daadwerkelijk uit op een afwijzing (111 van de 194). Bron: www.c2d.ch. Met 52 correctieve referenda in de afgelopen tien jaar is de inzet van het instrument wel aanzienlijk toegenomen. Als verklaringen worden genoemd de opmars van het populisme in Zwitsersland, gecombineerd met een lage handtekeningendrempel voor het aanvragen van een referendum (50.000 handtekeningen, 0,9 procent van de kiesgerechtigden; de Staatscommissie adviseerde voor Nederland 400.000 handtekeningen, 3,1 procent van de kiesgerechtigden) en een ontbrekende geldigheidsdrempel (die wat meer dan in het verleden plebiscitair avonturisme lijkt uit te nodigen). 
3 Voor andere typen volksstemmingen - het constitutioneel verplichte referendum en het volksinitiatief - vereist Zwitserland ook geen opkomst- of uitkomstdrempel, maar wordt de lat op een andere manier hoger gelegd: bij constitutioneel verplichte referenda en volksinitiatieven moet een dubbele meerderheid worden behaald - niet alleen onder de bevolking, maar ook onder de 26 kantons.

4 Uitkomstdrempels worden ook verbonden met andere typen referenda dan correctieve wetgevingsreferenda op burgerinitiatief. En ook hier zien we doorgaans hogere drempels als het gaat om de vaststelling of wijziging van constitutionele wetgeving, en vergelijkenderwijs wat lagere drempels als het gaat om reguliere wetgeving. Denemarken: uitkomstdrempel van 30 procent voor reguliere wetgeving aangevochten op initiatief van een institutionele minderheid; 40 procent voor constitutionele wetgeving. Zweden: 50 procent voor constitutionele wetgeving. Hongarije: uitkomstdrempel van 25 procent voor nationale referenda (was eerder een opkomstdrempel van 50 procent). Litouwen kent behalve de genoemde uitkomstdrempels ( 25 procent en 33,3 procent) nog een extra hoge uitkomstdrempel van 50 procent voor soevereiniteitskwesties, gekoppeld aan een eveneens zeer hoge opkomstdrempel van 75 procent (een speciale voorziening tegen inbreuken op de nationale soevereiniteit van Litouwen). Letland kent een vergelijkbare superdrempel voor constitutionele amendementen. Voor subnationale referenda in Duitsland wordt vaak een uitkomstdrempel van 25 procent gehanteerd. Bronnen: Hendriks e.a.,. 2019; Morel, L. \& Qvortrup, M. (red.) (2017). The Routledge Handbook to Referendums and Direct Democracy. Routledge; Aguiar-Conraria, L. \& Magalhaes, P.C. (2010). Referendum Design, Quorum Rules and Turnout. Public Choice, 144: 63-81; www.idea.int/data-tools/data/direct-democracy.

5 Eerder kwam ik, met Koen van der Krieken en Charlotte Wagenaar (zie Hendriks e.a., 2017, 178 e.v.) uit op een voorgestelde uitkomstdrempel van 25 procent. Bij 12,8 miljoen kiesgerechtigden moet het winnende kamp ruim 3,2 miljoen stemmen vergaren én het andere kamp achter zich laten. Als beide kampen aan elkaar gewaagd zijn, kan de opkomst richting de 50 procent worden opgestuwd, een respectabel opkomstniveau voor een one issue-stemming. Marc Pauly pleitte voor een generieke meerderheidsdrempel van 20 procent (Pauly, M. (2016, 15 maart). Repareer grote fout in referendumwet De Volkskrant). Tom van der Meer zat met een voorgestelde uitkomstdrempel van 15 procent nog iets lager (Meer, T. van der (2017). Niet de kiezer is gek. Spectrum, 99). Frank van Dooren pleitte als een van de weinigen (Dooren, F. van (2016, 9 december). Repareer weeffout in de Referendumwet. De Volkskrant) voor een uitzonderlijk hoge uitkomstdrempel van 50 procent. Daarmee komt de drempel zó hoog te liggen (bijna 6,5 miljoen Nederlanders zouden moeten tegenstemmen) dat het correctief referendum op voorhand obsoleet dreigt te worden.

\section{Literatuur}

Staatscommissie Parlementair Stelsel (2018). Lage drempels, hoge dijken. Amsterdam: Boom Amsterdam.

Aguiar-Conraria, L., \& Magalhaes, P.C. (2010). Referendum Design, Quorum Rules and Turnout. Public Choice, 144, 63-81.

Hendriks, F., Krieken, K. van der, \& Wagenaar, C. (2017). Democratische zegen of vloek: Aantekeningen bij het referendum. Amsterdam: Amsterdam University Press. 
Hendriks, F., Jacobs, D., \& Wagenaar, C. (2019). Referenderen en delibereren: Een verkenning van bindend correctieve referenda en combinaties met deliberatieve democratie. Tilburg University.

Meer, T. van der (2017). Niet de kiezer is gek. Amsterdam: Spectrum.

Morel, L., \& Qvortrup, M. (red.) (2017). The Routledge Handbook to Referendums and Direct Democracy. Oxfordshire: Routledge. 